\title{
Type 2 diabetes mellitus and medications for type 2 diabetes mellitus are associated with risk for and mortality from cancer in a German primary care cohort
}

\author{
Dorothee M. Baur $^{\text {a,b,c, }}{ }^{*}$, Jens Klotsche ${ }^{\text {d }}$, Ole-Petter R. Hamnvik ${ }^{\text {e,f }}$, Caroline Sievers ${ }^{\mathrm{g}}$, Lars \\ Pieper $^{\mathrm{d}}$, Hans-Ulrich Wittchen ${ }^{\mathrm{d}}$, Günter K. Stalla ${ }^{\mathrm{g}}$, Roland M. Schmid ${ }^{\mathrm{c}}$, Stefanos N. Kales \\ a,b Christos S. Mantzoros h,i
}

\begin{abstract}
a Harvard School of Public Health, Department of Environmental Health, Environmental and Occupational Medicine and Epidemiology (EOME),

Boston, MA, USA

b The Cambridge Health Alliance, Harvard Medical School, Employee Health and Industrial Medicine, Cambridge, MA, USA

c 2nd Medical Department, Klinkum rechts der Isar, Technical University of Munich, Germany d Institute of Clinical Psychology and Psychotherapy, Technische Universitaet Dresden, Germany e Department of Medicine, Brigham and Women's Hospital, Harvard Medical School Boston, MA, USA

f Division of Endocrinology, Diabetes and Hypertension, Department of Medicine, Brigham and Women's Hospital, Harvard Medical School, Boston, MA, USA

g Department of Endocrinology, Max Planck Institute of Psychiatry, Kraepelinstr. 2-10, 80804 Munich, Germany

h Division of Endocrinology, Diabetes, and Metabolism, Department of Medicine, Beth Israel Deaconess Medical Center, Boston, MA, USA

i Section of Endocrinology, Boston VA Healthcare System, Harvard Medical School, Boston, MA, USA
\end{abstract}

\begin{abstract}
There is growing evidence that patients with type 2 diabetes mellitus have increased cancer risk. We examined the association between diabetes, cancer, and cancer-related mortality and hypothesized that insulin sensitizers lower cancer-related mortality. Participants in the Diabetes Cardiovascular Risk and Evaluation: Targets and Essential Data for Commitment of Treatment study, a nationwide cross-sectional and prospective epidemiological study, were recruited from German primary care practices. In the cross-sectional study, subjects with type 2 diabetes mellitus had a higher prevalence of malignancies $(66 / 1308,5.1 \%)$ compared to nondiabetic subjects (185/6211,3.0\%) (odds ratio, 1.64; 95\% confidence interval, 1.12-2.41) before and after adjustment for age, sex, hemoglobin A1c, smoking status, and body mass index. Patients on metformin had a lower prevalence of malignancies, comparable with that among nondiabetic patients, whereas those on any other oral combination treatment had a 2fold higher risk for malignancies even after adjusting for possible confounders; inclusion of metformin in these regimens decreased the prevalence of malignancies. In the prospective analyses, diabetic patients in general and diabetic patients treated with insulin (either as monotherapy or in combination with other treatments) had a 2- and 4-fold, respectively, higher mortality rate than nondiabetic patients, even after adjustment for potential confounders (incidence of cancer deaths in patients with type 2 diabetes mellitus [2.6\%] vs the incidence of cancer deaths in patients without type 2 diabetes mellitus [1.2\%]). Our results suggest that diabetes and medications for diabetes, with the exception of the insulin sensitizer metformin, increase cancer risk and mortality.
\end{abstract}




\section{Introduction}

Epidemiological evidence is linking type 2 diabetes mellitus with several types of cancer, including hepatocellular, pancreatic, endometrial, colon, bladder, and breast cancer [1-3]. This is concerning because the incidence of type 2 diabetes mellitus is rising due to the aging population and the obesity epidemic [4]. Obesity, closely associated with the development of type 2 diabetes mellitus, also leads to an increased risk of many cancers [5].

The mechanisms linking diabetes and cancer have not been fully elucidated, but both hyperglycemia and hyperinsulinemia have been implicated. Insulin, through binding to the insulin and/or insulin-like growth factor, stimulates cell proliferation in vitro [3].

Observational studies in humans have shown an increased risk for cancer and cancer mortality in patients taking exogenous insulin and insulin secretagogues such as sulfonylureas [6-9]. In contrast, use of metformin, an insulin sensitizer that reduces circulating insulin levels, has been shown to significantly decrease the risk of cancer, cancer mortality, and cancer progression [10-13]. Evidence regarding other medications such as the thiazolidinediones or acarbose is conflicting but suggests that they do not alter cancer incidence [3,13].

Importantly, randomized controlled trials, which provide the highest quality evidence, have not supported an association between insulin therapy and cancer incidence or mortality [14]. Most of the reported evidence on the effect of antidiabetic treatment on cancer incidence or progression comes from either retrospective or case-control observational studies that do not incorporate the time sequence criterion for causality. There are only 3 prospective cohort studies and, importantly, only one retrospective cohort study with a nationwide population and primary care-based design, based on the British population [7].

No prior study has explored the effect of different treatment modalities in type 2 diabetic patients using both cross-sectional and longitudinal analyses providing joint evaluation of several antidiabetic medications with and without adjustments for several potential confounders in the context of a nationwide community-based study.

The aim of the present work is to investigate associations between antidiabetic therapies and the prevalence of and mortality from cancer in diabetic patients followed in primary care clinics randomly selected throughout Germany, in the context of a nationwide, populationbased prospective cohort study.

\section{Methods}

The research received institutional approval from the bioethics committee of the Technische Universitaet Dresden. All patients provided informed consent before participating in the study.

\subsection{Study population}

Participants in the Diabetes Cardiovascular Risk and Evaluation: Targets and Essential Data for Commitment of Treatment (DETECT) study, a large cross-sectional and prospective epidemiological study, were recruited from German primary care practices. The study was initiated to investigate the prevalence and comorbidity of diabetes mellitus, hypertension, dyslipidemia, coronary heart disease, and other associated medical conditions and behavioral and clinical risk factors. Methods, design, and previous results have been published in detail elsewhere [15-17]. In brief, a nationwide sample of 7053 randomly selected primary care 
physicians in Germany were invited to take part in a pre-study in the first quarter of 2003. The response rate was $60.2 \%$, yielding a total of 3795 physicians. Of these, 3188 opted to take part in the main study. The sample was representative of primary care physicians in Germany in terms of regional distribution, age, years of experience, specialty orientation, and patient load per day [17].

On a target day in September 2003, the enrolled primary care physicians recorded the health state of 55518 consecutively enrolled patients (response rate $93.5 \%$ ) by using an extensive standardized physician clinical interview and a patient self-report questionnaire.

For the longitudinal arm of this study, a random subset of 7519 patients who had undergone a more intensive standardized laboratory assessment was included. They were followed after 1 year in 2004and after 5 years in 2007 to 2008. Thirty-seven patients with type 1 diabetes mellitus were excluded, leaving 7482 patients for the baseline, cross-sectional analyses.

For the prospective analyses, 693 participants were lost to follow-up and did not provide information regarding cancer-related mortality. Baseline characteristics of the excluded patients were not statistically significantly different from the rest of the group. This left 6826 patients for the prospective study.

\subsection{Assessment of clinical and laboratory variables}

Type 2 diabetes mellitus was defined by the clinicians indicating a "definite" diagnosis of diabetes mellitus or the use of antidiabetic medications recorded by the clinician in the standardized clinical interview. The diagnosis of cancer and the type of cancer were based on clinicians rating the diagnosis as "definite." Both diagnoses of "cancer" and "type 2 diabetes" were confirmed using nosologic criteria from the International Statistical Classification of Diseases and Related Health Problems, 10th Revision. Cancer-related mortality was reported by the clinician and reconfirmed by examination of death certificates. Smoking status was based on physicians' reports in the standardized clinical interview.

Height and weight were measured by the physicians using a standardized protocol [15], and body mass index (BMI) was calculated accordingly.

Standardized blood samples and a defined set of laboratory markers were collected between 8:00 and 10:00 AM in the fasting state, and transported at room temperature within 24 hours to the study's central laboratory at the Medical University of Graz, Austria. After arrival, the samples were centrifuged immediately and serum and plasma were stored at $-80^{\circ} \mathrm{C}$ until further processing [17]. Hemoglobin A1c (HbA 1c) was determined chromographically using the Arkray ADAMS A1c HA-8160 analyzing system (Arkray, Kyoto, Japan), using secondary standards as recommended by the manufacturers $[15,17]$.

\subsection{Statistical analysis}

All statistical analyses were performed using STATA 11.0 (Stata, College Station, TX).

A summary of the study variables and descriptive characteristics are presented as mean \pm SD or as number of patients and percentages. Baseline characteristics between patients with cancer vs patients without cancer and patients with type 2 diabetes mellitus vs those without type 2 diabetes mellitus were compared using $t$ test for continuous variables and Pearson $\chi^{2}$ test for categorical variables. 
Logistic regression analyses were applied to study the cross-sectional association of cancer with type 2 diabetes mellitus or diabetes therapy. Odds ratios and 95\% confidence intervals (CIs) were presented for unadjusted and adjusted models. Cancer-related mortality was modeled by Cox regression analyses with follow-up duration as the time variable. Hazard ratios and 95\% CIs were presented for unadjusted and adjusted models. The proportional hazard assumption was confirmed by Schoenfeld residuals. Covariates included in the adjusted models include age, sex, HbA1c, smoking status, and BMI at baseline. Two-sided P values less than .05 were used to infer statistical significance.

\section{Results}

\subsection{Baseline cohort description and cross-sectional analyses}

The baseline characteristics of the study sample are reported in Table 1; 1308 (17.4\%) patients had type 2 diabetes mellitus and $251(3.3 \%)$ had cancer at baseline. The prevalence of cancer was $5.1 \%$ in patients with type 2 diabetes mellitus and $3.0 \%$ in patients without type 2 diabetes mellitus $(\mathrm{P}<.001)$. The subgroup of patients with type 2 diabetes mellitus and cancer had a mean age of $70.4 \pm 8.0$ years; a mean BMI of $28.3 \pm 4.2 \mathrm{~kg} / \mathrm{m} 2$; and the mean levels of HbA1c and plasma glucose were $6.4 \% \pm 1.0 \%$ and $130.2 \pm 45.0 \mathrm{mg} / \mathrm{dL}$, respectively. In contrast, patients without cancer in the type 2 diabetes mellitus group at baseline were 66.4 \pm 10.0 years old and had a mean BMI, HbA1c, and plasma glucose of $29.8 \pm 5.0 \mathrm{~kg} / \mathrm{m} 2,6.8 \pm$ 1.2 , and $147.8 \pm 56.0 \mathrm{mg} / \mathrm{dL}$, respectively. The differences in age, plasma glucose, and $\mathrm{HbA1c}$ remained statistically significant after adjustment for sex, BMI, and/or age (where appropriate), whereas the difference of BMI was not statistically significant after adjustment.

The proportion of diabetic patients receiving any antidiabetic treatment was $60.9 \%$ in patients with cancer compared with $74.9 \%(\mathrm{P}=.014)$ in those without cancer. The insulin and metformin treatment rates were lower in the subgroup of patients with type 2 diabetes mellitus and cancer compared with those in patients without cancer (insulin, $18.8 \%$ vs $27.1 \%$; metformin, $31.3 \%$ vs $42.4 \%$ ), but this difference did not remain significant after controlling for age, BMI, and HbA1c (data not shown). Table 2 presents the cross-sectional analyses. At baseline, 251 patients had cancer, 66 of whom also had type 2 diabetes mellitus. Hence, the odds ratio (OR) for having cancer was 1.72 (95\% CI, 1.29-2.29) in patients with type 2 diabetes mellitus compared with that in patients without diabetes, which remained statistically significant even after adjusting for age, sex, HbA1c, smoking, and BMI (OR, 1.64; 95\% CI, $1.12-2.41)$.

Patients with type 2 diabetes mellitus who received monotherapy with insulin had an OR of 0.93 (95\% CI, 0.41-2.13) for cancer compared to patients without diabetes. Similarly, when examining all patients taking insulin (monotherapy or combination therapy), the OR was 1.08 (95\% CI, 0.59-1.95) for having cancer. However, any other monotherapy or combination treatment excluding insulin was associated with an elevated OR of 1.51 (95\% CI, 1.00-2.28) compared to that in patients without diabetes. Similar results were found when only those on combination treatment with insulin and another agent and those on combination treatment with oral antidiabetic agents are compared to patients without type 2 diabetes mellitus.

Compared to patients without diabetes mellitus, patients with type 2 diabetes mellitus on monotherapy with metformin tended to have lower cancer prevalence $(\mathrm{OR}, 1.04 ; 95 \% \mathrm{CI}$, 0.46- 2.39) than patients not on metformin therapy (OR, 1.44; 95\% CI, 0.89-2.34). When looking at all patients who are treated with metformin, including both monotherapy and 
combination therapy, the OR was 1.19 (95\% CI, 0.7-2.04) compared to that in patients without type 2 diabetes mellitus. This compared to an OR of 2.26 (95\% CI, 1.24-4.13) for patients taking any other diabetes treatment excluding metformin, which was statistically significant in the crude analysis compared to the OR for patients without type 2 diabetes mellitus. Furthermore, patients with monotherapy or combination treatment excluding metformin had a higher proportion of cancer (OR, 1.89; 95\% CI, 0.87-4.13) compared to patients with type 2 diabetes mellitus and monotherapy or combination treatment including metformin (data not shown).

Restricting the analysis to those taking only oral medications, a higher OR for cancer was seen in those on combination treatment with any oral medication excluding metformin (OR, 3.88; 95\% CI, 1.16-12.98), which persisted after multivariate adjustment (OR, 4.04; 95\% CI, 1.07-15.26). For those on any oral medication including metformin, the OR was $1.32(95 \%$ CI, 0.67-2.61) compared to that in patients without type 2 diabetes mellitus, respectively.

Treatment with glucosidase inhibitors, sulfonylureas, or meglitinides increased the risk for malignancies by 1.59 -fold (95\% CI, 1.01-2.5) compared to patients without type 2 diabetes mellitus. This increase did not persist after adjustment for multivariate confounders. Patients with type 2 diabetes mellitus and monotherapy with metformin had a lower proportion of cancer (OR, 0.66; 95\% CI, 0.26-1.64) compared to patients with type 2 diabetes mellitus and treatment with glucosidase inhibitors, sulfonylureas, or meglitinides (data not shown).

\subsection{Prospective cohort analyses}

Table 3 presents the data relating to cancer-related mortality data at the 4- to 5-year followup. The cancer-related mortality rate was $1.2 \%(\mathrm{n}=68)$ in subjects without type 2 diabetes mellitus and $2.6 \%(\mathrm{n}=32)$ in subjects with type 2 diabetes mellitus (hazard ratio [HR], 2.10; 95\% CI, 1.38-3.20).

In patients treated with insulin monotherapy, the crude HR was 4.03 (95\% CI, 2.08-7.83) and the association remained significant after adjusting for confounders (HR, 3.87; 95\% CI, 1.539.81). Similar findings, including persistent significance after adjustment for confounders, were seen when considering all patients who were taking any monotherapy or combination treatment including insulin (HR, 4.24; 95\% CI, 2.52-7.12) or any combination treatment including insulin (HR, 4.52; 95\% CI, 2.18-9.40).

The HR for cancer-related death in patients on monotherapy with metformin (HR, 1.34; 95\% CI, 0.42-4.25) was lower than the HR in patients who were on any other treatment regimen that did not include metformin (crude HR, 3.51; 95\% CI, 2.09-5.88; confounder-adjusted HR, $2.51 ; 95 \% \mathrm{CI}, 1.2-5.27)$. Similar results were seen when looking at any treatment regimen that included metformin or that did not include metformin. If looking only at oral combination treatment regimens, those that did not include metformin had a HR for mortality of 7.36, which approached significance after multivariate analysis $(\mathrm{HR}, 3.66 ; \mathrm{P}=.09)$.

Treatment with glucosidase inhibitors, sulfonylureas, and meglitinides was associated with increased mortality when compared to that in patients without type 2 diabetes mellitus (HR, $1.88 ; 95 \% \mathrm{CI}, 0.97-3.63)$. Compared to treatment with glucosidase inhibitors, sulfonylureas, and meglitinides, patients with type 2 diabetes mellitus and monotherapy with metformin had a lower cancer-related mortality (HR, 0.71; 95\% CI 0.2-2.59) (data not shown). 


\section{Discussion}

We have studied a large, nationwide primary care-based cohort, representative of German primary care practices, to identify the prevalence of malignancies among patients with type 2 diabetes mellitus, cross-sectional associations between specific antidiabetic treatments and prevalence of malignancies, as well as prospective associations between type 2 diabetes mellitus, diabetes-specific treatments, and cancer mortality.

Subjects with type 2 diabetes mellitus had a higher prevalence of malignancies compared to nondiabetic subjects in the same primary care practices (OR, 1.64; 95\% CI, 1.12-2.41) before and after adjustment for age, sex, HbA1c, smoking status, and BMI. Moreover, we found that patients on oral medications including glucosidase inhibitors, sulfonylureas, and meglitinides had a prevalence of malignancies that is similar to that observed for all patients with type 2 diabetes mellitus, that is, nearly 2 -fold higher than in nondiabetic patients. In contrast, patients on the insulin sensitizer metformin had a relatively lower prevalence of malignancies, which was comparable to that observed among nondiabetic patients. Similarly, patients on any combination treatment including oral medications other than metformin had a 2-fold higher risk for malignancies even after adjusting for possible confounders, whereas inclusion of metformin in any combination regimen decreased the prevalence of malignancies to that of nondiabetic patients.

Interestingly, in our study, patients on insulin had a similar prevalence of malignancies to the nondiabetic patients but considerably higher mortality in prospective follow-up, suggesting 2 possible underlying mechanisms. Either insulin exposure does not initiate carcinogenesis, but may play a role in stimulating cancer growth and accelerating growth over time, or insulin therapy may cause higher mortality through other mechanisms.

Furthermore, in the prospective analyses, we showed that diabetic patients in general have a 2-fold higher cancer mortality than nondiabetic patients and that among diabetic patients, those treated with insulin (either as monotherapy or in combination with other treatments) have a 4-fold higher cancer-related mortality that remained significant after adjustment for potential confounders including age, sex, BMI, smoking status, and glycemic control. Monotherapy or combination therapy with any oral medications for type 2 diabetes mellitus, except metformin, was associated with increased mortality by several-fold, whereas monotherapy with metformin resulted in mortality comparable to that in nondiabetic patients. Monotherapy and/or oral combination treatment including metformin reduced the mortality rate to levels comparable to those seen in patients without type 2 diabetes mellitus.

On the other hand, metformin might more likely be prescribed in the beginning of the therapy strategy for patients with type 2 diabetes mellitus; it might be possible that these cases are at lower cancer risk because of their yet milder disease.

The suppression of hepatic glucose production is seen as the major action of metformin. In addition, it has anti-inflammatory and antioxidant properties. Nath et al [18] recently emphasized this very important role with metformin-induced activation of adenosine monophospate-activated protein kinase in the brains of mice with experimental autoimmune encephalomyelitis and in macrophages. Metformin inhibited the expression of inflammatory cytokines and their mediators [18].

Our study adds to an emerging literature on the interactions between diabetes mellitus and cancer. We confirm findings from other recent studies reporting an increased risk of cancer, 
increased cancer-related mortality, and increased overall mortality in diabetic patients compared to nondiabetic patients $[1,19,20]$.

A number of studies have examined the association between antidiabetic agents and the increased prevalence of cancer and cancer-related mortality in diabetic patients. Despite some inconsistency in the results, case-control studies [10,13], retrospective cohort studies [7-9], and prospective cohort studies $[6,11,12]$ have mostly shown an association between exposure to insulin or insulin secretagogues and increased prevalence of cancer $[8,13]$, increased cancer-related mortality [6], and increased progression of solid tumors [7,9]. In contrast, exposure to metformin appears to be neutral or protective, with a reduced prevalence of cancer [12] and reduced cancer-related mortality [11,12]. However, there have been several other studies that have failed to show increased cancer mortality in patients taking insulin $[11,12]$ or a sulfonylurea [12].

The findings from our study appear to support the theory that the increased risk of cancer mortality in diabetic patients is related to hyperinsulinemia and the effect of insulin on cell proliferation, whereas metformin, which decreases insulin resistance and hyperinsulinemia, has a protective effect. Data from emerging randomized clinical trials are limited by the duration and size of these trials [14], whereas data from prior observational studies are, by design, confounded by either known and/or unknown confounders that could not be controlled for. Patients who are taking insulin are likely to be sicker and have more complications from their diabetes, as insulin treatment is usually initiated later in the course of the disease. Hence, their cancer may have progressed more and/or they may be less able to tolerate cancer-related complications or anticancer treatments. Similarly, metformin is the recommended first-line therapy for diabetes mellitus and has multiple contraindications limiting its use in people with comorbidities, hence introducing a bias for the healthiest patients. Because the gold standard of clinical trials is difficult to perform in the near future, community and primary case- based prospective cohort studies can reduce or eliminate some important confounding factors.

Our study has several strengths. Unlike most other studies, this prospective cohort is community-based and encompasses a large geographic area in central Europe. There is only one previous nationwide prospective cohort study that was population-based [7]. Our study is a nationwide prospective cohort study based on primary care practices and thus offers distinct advantages over prior studies. Data were collected by primary care physicians who were not aware of the hypothesis of the underlying study. Cancer mortality was assessed by reports submitted by primary care physicians and also confirmed by examination of death certificates. Data were stored and analyzed by blinded personnel. The number of participants in the study is large enough to provide adequate statistical power. Thus, our results are generalizable to the central European population who formed the study base for the DETECT cohort.

The weaknesses of the study include a relatively short follow-up period of 4 to 5 years. Therefore, potential long-term effects of the medications remain unknown. Information concerning duration and dose of diabetes medication was not recorded in the described study. The number of incident cancer cases in patients with and without type 2 diabetes mellitus is small because of the overall design of the study and the relatively short follow-up period. However, the analyses showed clearly significant results calling for larger studies to further describe the effects of glucose-lowering medications.

Furthermore, the assessment of cancer prevalence or incidence was based on a clinical rating in a standardized questionnaire administered by the physicians. It is thus possible that subjects with suboptimal follow-up might have provided incomplete information with respect to 
cancer incidence and prevalence. However, there is no evidence that people on metformin would have a different follow-up for their diabetes than those on other medications; hence, we do not anticipate bias in this respect. Moreover, we have adjusted for a surrogate marker of appropriate follow-up (ie, glycemic control, HbA1c) in addition to socioeconomic and demographic variables and we have detected no major confounding on the basis of these variables. We expect limited misclassification of reporting of medications. Any such misclassification would be expected to be random and would have resulted in suppressed effect estimates and lower P values, but it could not have resulted in the statistically significant results observed herein. Although this is a prospective cohort study that incorporates the time sequence criterion for causality, its observational nature cannot prove causality beyond any doubt.

These findings are of clinical importance given the dramatically increasing prevalence of type 2 diabetes mellitus during the last decades; according to the World Health Organization, the current prevalence of type 2 diabetes mellitus is approximately 170 million people and the number is expected to rise up to 360 million worldwide by the year 2030 [4,21]. If our data are extrapolated to people with diabetes in other nations and continents, this would result in a much higher prevalence of malignancies in the future. Thus, in addition to larger and longer observational cohort studies and larger cohort studies, randomized, placebo-controlled metformin administration trials are needed to assess any beneficial effects of metformin in relation to cancer-related mortality among diabetic patients. If causality is proven by future interventional studies, metformin may emerge as a potential preventive therapy.

\begin{tabular}{|c|c|c|c|c|c|c|}
\hline & \multicolumn{2}{|c|}{ Patients with DM2 } & \multirow[t]{2}{*}{$P^{*}$} & \multicolumn{2}{|c|}{ Patients without DM2 } & \multirow[t]{2}{*}{$P^{b}$} \\
\hline & Cancer & No cancer & & Cancer & No cancer & \\
\hline & $66(5.1 \%)$ & $1,202(95.0 \%)$ & & $185(3.0 \%)$ & $6,026(97.0 \%)$ & \\
\hline$A g E(y)$ & $70.4 \pm 8.0^{+}$ & $66.4 \pm 10.0$ & $\mathrm{c.001}$ & $65.5 \pm 11.6$ & $55.5 \pm 14.4^{\neq}$ & $\mathrm{COO1}$ \\
\hline $\mathrm{BMI}\left(\mathrm{kg} / \mathrm{m}^{2}\right)$ & $28.3 \pm 4.2^{*}$ & $29.8 \pm 5.0$ & .01 & $26.7 \pm 4.2$ & $26.6 \pm 4.7^{*}$ & .79 \\
\hline $\mathrm{HbA}_{\mathrm{Le}}(\%)$ & $6.4 \pm 10^{\dagger}$ & $6.8 \pm 1.2$ & .003 & $5.4 \pm 0.4$ & $5.3 \pm 0.5^{\neq}$ & 21 \\
\hline Plasma glucose (mg/di.) & $130.2 \pm 45.0^{*}$ & $1478 \pm 56.0$ & .002 & $94.3 \pm 15.8$ & $93.3 \pm 21.2^{\neq}$ & .41 \\
\hline Any antidiabetic treatment & $39(50.9 \%)$ & $906(74.9 \%)$ & .014 & & & \\
\hline Ghucosidase blockers & $5(7.8 \%)$ & $80(6.6 \%)$ & .71 & & & \\
\hline Sulfonylureas & $17(26.6 \%)$ & $363(30.0 \%)$ & 56 & & & \\
\hline Insulin & $12(18,8 \%)$ & $327(27.1 \%)$ & .15 & & & \\
\hline Metformin & $20(31.3 \%$ & $512(42.4 \%)$ & .08 & & & \\
\hline Meglitinides & $2(3.1 \%)$ & $41(3.4 \%)$ & .91 & & & \\
\hline Thiazolidinediones & $3(4.7 \%)$ & $49(4.1 \%)$ & 8 & & & \\
\hline \multicolumn{7}{|c|}{ 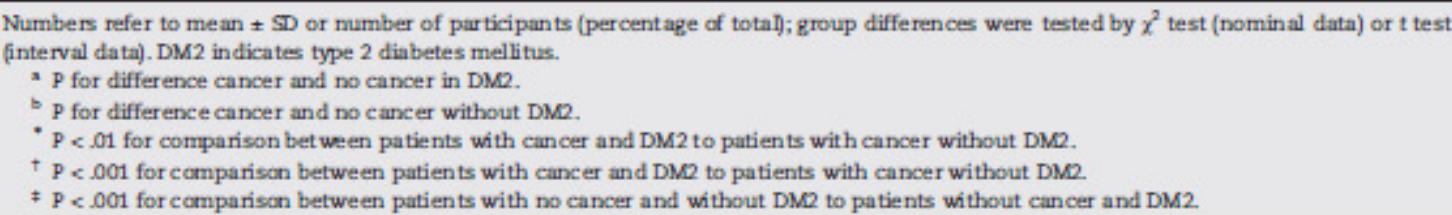 } \\
\hline
\end{tabular}


Table 2 - Cross-sectional association between type 2 dilabetes mellitus and cancer at baseline (N = 7519)

\begin{tabular}{|c|c|c|c|c|c|c|c|c|c|c|c|c|c|c|c|c|}
\hline & \multirow{2}{*}{$\begin{array}{l}\begin{array}{c}\text { Diagnosis } \\
\text { of cancer }\end{array} \\
\mathrm{N}(\%)\end{array}$} & \multicolumn{3}{|c|}{ Unadjusted } & \multicolumn{3}{|c|}{$\begin{array}{l}\text { Adjusted for } \\
\text { sex and age }\end{array}$} & \multicolumn{3}{|c|}{$\begin{array}{l}\text { Adjusted for } \\
\text { age, sex, and } \\
\mathrm{HbA}_{1 \mathrm{c}}\end{array}$} & \multicolumn{3}{|c|}{$\begin{array}{l}\text { Adjusted for } \\
\text { age, sex, } \\
\mathrm{HbA}_{10} \text { and } \\
\text { smoking } \\
\text { status }\end{array}$} & \multicolumn{3}{|c|}{$\begin{array}{l}\text { Adjusted for } \\
\text { age, sex, } \mathrm{HbA}_{1 o} \\
\text { smoking status, } \\
\text { and BMI }\end{array}$} \\
\hline & & $\overline{\mathrm{OR}}$ & $95 \% \mathrm{Cl}$ & $P$ & $\overline{O R}$ & $95 \% \mathrm{Cl}$ & $P$ & $\mathrm{OR}$ & $95 \% \mathrm{Cl}$ & $P$ & OR & $95 \% \mathrm{Cl}$ & $P$ & $\mathrm{OR}$ & $95 \% \mathrm{Cl}$ & P \\
\hline No DM2 & $185(3.0 \%)$ & 1.00 & & & 1.00 & & & 1.00 & & & 1.00 & & & 100 & & \\
\hline DMD & $66(5.1 \%)$ & 1.72 & $1.29 \cdot 2.29$ & $<001$ & 1.13 & $0.84-1.52$ & .44 & 1.64 & $1.12 \cdot 2.40$ & .01 & 1.61 & $1.10-2.36$ & .01 & 1.64 & $1.12 \cdot 2.41$ & .01 \\
\hline No DM2 & $185(3.0 \%)$ & 1.00 & & & 1.00 & & & 1.00 & & & 1.00 & & & 100 & & \\
\hline $\begin{array}{l}\text { DMa: monother apy } \\
\text { with insulin }\end{array}$ & $6(28 \%)$ & 0.93 & $0.41 \cdot 2.13$ & .87 & 0.69 & $0.30 \cdot 1.59$ & 39 & 1.21 & $0.47 \cdot 3.09$ & .69 & 1.20 & $0.47 \cdot 3.10$ & .70 & 1.19 & $0.46-3.08$ & .71 \\
\hline $\begin{array}{l}\text { DMV: any other } \\
\text { treatment }\end{array}$ & $27(4.5 \%)$ & 1.51 & $100 \cdot 228$ & .05 & 0.96 & $0.63-1.66$ & 86 & 1.39 & $0.83 \cdot 2.34$ & 21 & 1.37 & $0.82-2.30$ & 23 & 139 & $0.82-2.34$ & .22 \\
\hline No DM2 & $185(3.0 \%)$ & 1.00 & & & 1.00 & & & 100 & & & 100 & & & 100 & & \\
\hline $\begin{array}{l}\text { DMQ: monother apy or } \\
\text { combination treatment } \\
\text { with insulin }\end{array}$ & $12(3.2 \%)$ & 1.08 & $0.59 \cdot 1.95$ & .81 & 0.76 & $0.41-1.38$ & 36 & 1.31 & $0.63-272$ & .47 & 1.29 & $0.62-2.69$ & 50 & 129 & $0.62-2.71$ & 50 \\
\hline $\begin{array}{l}\text { DM2: any treatment } \\
\text { without insulin }\end{array}$ & $27(4.5 \%)$ & 1.51 & $100-2.28$ & .05 & 0.96 & $0.63-1.46$ & 86 & 1.38 & $0.83-2.30$ & 21 & 1.36 & $0.82-2.27$ & 23 & 138 & $0.82-2.30$ & .22 \\
\hline No DMQ & $185(3.0 \%)$ & 1.00 & & & 1.00 & & & 100 & & & 1.00 & & & 100 & & \\
\hline $\begin{array}{l}\text { DME: oral cambination } \\
\text { treatment }\end{array}$ & $12(4.7 \%)$ & 1.58 & $0.87 \cdot 2.87$ & .13 & 1.06 & $0.58-1.92$ & 86 & 1.78 & $0.87-3.66$ & .12 & 1.75 & $0.85-3.58$ & .13 & 1.76 & $0.86-3.61$ & .12 \\
\hline $\begin{array}{l}\text { DM2: comtination } \\
\text { ther apy including } \\
\text { insulin }\end{array}$ & $6(3.8 \%)$ & 1.27 & $0.55 \cdot 2.91$ & .57 & 0.83 & $0.36-1.93$ & .67 & 1.69 & $0.66 \cdot 4.30$ & 28 & 1.61 & $0.63-4.09$ & 32 & 160 & $0.63-4.11$ & 32 \\
\hline № DM2 & $185(3.0 \%)$ & 1.00 & & & 1.00 & & & 1.00 & & & 100 & & & 100 & & \\
\hline $\begin{array}{l}\text { DMV: monother apy } \\
\text { with metformin }\end{array}$ & $6(3.1 \%)$ & 1.04 & $0.46 \cdot 2.39$ & .92 & 0.70 & $0.31-1.60$ & .40 & 0.93 & $0.39-222$ & 87 & 0.91 & $0.38-2.17$ & 83 & 0.92 & $0.39-2.20$ & 85 \\
\hline $\begin{array}{l}\text { DME: any treatment } \\
\text { excluding metformin }\end{array}$ & $19(4.3 \%)$ & 1.4 & $0.89 \cdot 2.34$ & .14 & 0.92 & $0.56 \cdot 1.52$ & .75 & 1.43 & $0.75-274$ & 28 & 1.43 & $0.74-275$ & 29 & 142 & $0.73 \cdot 2.74$ & 30 \\
\hline No DMQ & $185(3.0 \%)$ & 1.00 & & & 1.00 & & & 1.00 & & & 1.00 & & & 100 & & \\
\hline $\begin{array}{l}\text { DME- monother apy or } \\
\text { cambination treatment } \\
\text { including metformin }\end{array}$ & $15(3.6 \%)$ & 1.19 & $0.70 \cdot 206$ & .52 & 0.81 & $0.48-1.38$ & .44 & 1.19 & $0.64-223$ & 58 & 1.17 & $0.63-2.19$ & .62 & 1.19 & $0.63-2.23$ & 59 \\
\hline $\begin{array}{l}\text { DM2: monotherapy or } \\
\text { combination treatment } \\
\text { excluding metformin }\end{array}$ & $12(6.5 \%)$ & 226 & $1.24-4.13$ & .01 & 126 & $0.57-2.37$ & 47 & 1.89 & $0.93-3.84$ & .08 & 1.87 & $0.91-3.82$ & .99 & 1.85 & $0.90-3.80$ & .09 \\
\hline No DM2 & $185(3.0 \%)$ & 100 & & & 100 & & & 1.00 & & & 1.00 & & & 1.00 & & \\
\hline $\begin{array}{l}\text { DM2: onal combination } \\
\text { treatment including } \\
\text { metformin }\end{array}$ & $9(3.9 \%)$ & 132 & $0.67-2.61$ & .43 & 0.90 & $0.46-1.77$ & 75 & 156 & $0.72-3.35$ & 26 & 1.52 & $0.71-3.28$ & 28 & 1.53 & $0.71-3.31$ & .28 \\
\hline $\begin{array}{l}\text { DM2: onl combination } \\
\text { treatment exchuding } \\
\text { metformin }\end{array}$ & $3(10.7 \%)$ & 3.88 & $1.16-12.98$ & .03 & 2.32 & $0.66-8.15$ & 19 & 4.00 & $105-15.28$ & .04 & 4.05 & $109-15.13$ & .04 & 4.04 & $1.07-15.26$ & .04 \\
\hline № DM2 & $185(3.0 \%)$ & 100 & & & 100 & & & 1.00 & & & 1.00 & & & 1.00 & & \\
\hline $\begin{array}{l}\text { DM2: treatment with } \\
\text { glucosidase in hivitars, } \\
\text { sulfanylureas or } \\
\text { meglitinides }\end{array}$ & $22(4.79)$ & 159 & $1.01-2.50$ & .04 & 0.98 & $0.62-1.55$ & 92 & 1.52 & $0.87 \cdot 2.68$ & .14 & 1.51 & $0.86-2.66$ & .16 & 152 & $0.96-2.68$ & .15 \\
\hline $\begin{array}{l}\text { DM2: monothenapy } \\
\text { with metfarmin }\end{array}$ & $6(3.1 \%)$ & 104 & $0.46-2.39$ & 92 & 0.70 & $0.31-1.60$ & .40 & 0.97 & $0.41-2.28$ & 94 & 0.94 & $0.40-2.22$ & 89 & 0.96 & $0.41-2.25$ & .92 \\
\hline $\begin{array}{l}\text { DM2: any other } \\
\text { medication }\end{array}$ & $11(3.5 \%)$ & 1.16 & $0.62-2.15$ & .64 & 0.85 & $0.45-1.60$ & 62 & 1.49 & $0.69-3.20$ & 31 & 1.47 & $0.68-3.15$ & 33 & 1.48 & $0.69-3.18$ & .32 \\
\hline
\end{tabular}




\begin{tabular}{|c|c|c|c|c|c|c|c|c|c|c|c|c|c|c|c|c|}
\hline & \multirow{2}{*}{$\begin{array}{c}\begin{array}{c}\text { Cancer-related } \\
\text { mortality }\end{array} \\
\mathrm{n}(\%)\end{array}$} & \multicolumn{3}{|c|}{ Unadjusted } & \multicolumn{3}{|c|}{$\begin{array}{l}\text { Adjusted for sex } \\
\text { and age }\end{array}$} & \multicolumn{3}{|c|}{$\begin{array}{l}\text { Adjusted for } \\
\text { age, sex, and } \\
\text { HbA }\end{array}$} & \multicolumn{3}{|c|}{$\begin{array}{l}\text { Adjusted for } \\
\text { age, sex, } \mathrm{HbA}_{10} \\
\text { and smoking } \\
\text { status }\end{array}$} & \multicolumn{3}{|c|}{$\begin{array}{l}\text { Adjusted for } \\
\text { age, sex, HbA } 10 \\
\text { smoking status, } \\
\text { and BMI }\end{array}$} \\
\hline & & HR & $95 \% \mathrm{Cl}$ & $P$ & $\mathrm{HR}$ & $95 \% \mathrm{Cl}$ & $P$ & $\mathrm{HR}$ & $95 \% \mathrm{Cl}$ & $P$ & $\mathrm{HR}$ & $95 \% \mathrm{Cl}$ & $P$ & HR & $95 \% \mathrm{Cl}$ & $P$ \\
\hline No DM2 & $\operatorname{QBP}(12 \%)$ & 100 & & & 100 & & & 100 & & & 1.00 & & & 1.00 & & \\
\hline DM2 & $32(26 \%)$ & 210 & $1.38-3.20$ & .001 & 1.38 & $0.99-2.14$ & .15 & 1.24 & $0.74 \cdot 208$ & .41 & 1.26 & $0.75 \cdot 212$ & 39 & 1.25 & $0.74 \cdot 213$ & .41 \\
\hline No DMQ & $\Leftrightarrow(12 \%)$ & 100 & & & 100 & & & 100 & & & 1.00 & & & 1.00 & & \\
\hline $\begin{array}{l}\text { DM2 monotherapy } \\
\text { with insulin }\end{array}$ & $10(5.1 \%)$ & 4.03 & $2.08 \cdot 7.83$ & $=.001$ & 3.02 & $1.56-5.85$ & .001 & 3.74 & $1.50-9.28$ & .01 & 3.89 & $1.53 \cdot 9.82$ & .004 & 3.87 & 1.53 - 9.81 & .004 \\
\hline $\begin{array}{l}\text { DM2: any other treatment } \\
\text { No DM2 }\end{array}$ & $\begin{array}{r}9(1.6 \%) \\
\otimes(1.2 \%)\end{array}$ & $\begin{array}{l}1.28 \\
1.00\end{array}$ & $0.64-2.57$ & 28 & $\begin{array}{l}0.79 \\
1.00\end{array}$ & $0.39-1.59$ & 51 & $\begin{array}{l}0.90 \\
1.00\end{array}$ & $0.90-2.03$ & $\$ 1$ & $\begin{array}{l}0.92 \\
1.00\end{array}$ & $0.40-2.10$ & 85 & $\begin{array}{l}0.92 \\
1.00\end{array}$ & $0.40-2.11$ & s4 \\
\hline $\begin{array}{l}\text { DM2 monotherapy or } \\
\text { cambination treatment } \\
\text { with insulin }\end{array}$ & 18 (5.1\%) & 4.24 & $2.52 \cdot 7.12$ & $<.001$ & 3.09 & $1.83-5.23$ & $<001$ & 3.86 & $1.80-8.25$ & .001 & 3.99 & $1.83 \cdot 8.70$ & $<.001$ & 3.96 & $182-8.63$ & .001 \\
\hline $\begin{array}{l}\text { DM2: any treatment } \\
\text { without insulin }\end{array}$ & $9(1.6 \%)$ & 1.28 & $0.64-2.57$ & 48 & 0.80 & $0.40-1.62$ & .54 & 0.92 & $0.42 \cdot 2.05$ & 85 & 0.95 & $0.42-2.12$ & 89 & 0.93 & $0.41-211$ & 87 \\
\hline No DME & $68(12 \%)$ & 1.00 & & & 100 & & & 100 & & & 1.00 & & & 1.00 & & \\
\hline $\begin{array}{l}\text { DM2 onal combination } \\
\text { treatment }\end{array}$ & $3(1.3 \%)$ & 1.03 & $0.33-3.26$ & 96 & 0.68 & $0.22 \cdot 2.15$ & 51 & 0.70 & $0.19 \cdot 2.58$ & .59 & 0.71 & $0.19 \cdot 2.63$ & .61 & 0.70 & $0.19-2.63$ & .60 \\
\hline $\begin{array}{l}\text { DM2: combination therapy } \\
\text { including insulin }\end{array}$ & $8(5.2 \%)$ & 4.52 & $2.18-9.40$ & $<.001$ & 3.12 & $1.48-6.59$ & .003 & 3.22 & $1.15-9.04$ & .03 & 3.26 & $1.14-9.28$ & .03 & 3.25 & $1.15 \cdot 9.19$ & .03 \\
\hline No DMQ & $68(12 \%)$ & 100 & & & 100 & & & 100 & & & 1.00 & & & 1.00 & & \\
\hline $\begin{array}{l}\text { DM2: monother apy } \\
\text { with metformin }\end{array}$ & $3(17 \%)$ & 1.34 & $0.42-4.25$ & .62 & 0.86 & $0.27-2.79$ & .91 & 0.92 & $0.28-2.95$ & 38 & 0.92 & $0.28-2.99$ & 89 & 0.90 & $0.28-2.92$ & 86 \\
\hline DM2 any treatment excluding metformin & $18(4.4 \%)$ & 3.51 & $2.09-5.88$ & $<.001$ & 2.24 & $1.32-3.80$ & .003 & 248 & $1.18-5.18$ & .20 & 2.52 & $1.20 \cdot 5.29$ & .02 & 2.51 & $1.20 \cdot 5.27$ & .20 \\
\hline $\begin{array}{l}\text { DM2 monother apy } \\
\text { or comtination treatment } \\
\text { including metformin }\end{array}$ & $4(10 \%)$ & 0.82 & $0.30-2.25$ & .70 & 0.54 & $0.19-1.49$ & 23 & 0.54 & $0.19 \cdot 1.59$ & 27 & 0.55 & $0.18-1.64$ & 28 & 0.54 & $0.18 \cdot 1.63$ & 28 \\
\hline $\begin{array}{l}\text { DM2: monother apy or } \\
\text { cambination treatment } \\
\text { excluding metformin }\end{array}$ & $5(3.0 \%)$ & 2.35 & $0.95-5.80$ & .06 & 1.27 & $0.51-3.15$ & .61 & 1.28 & $0.41-4.00$ & 67 & 1.30 & $0.41 \cdot 4.05$ & .66 & 1.30 & $0.42 \cdot 4.07$ & .65 \\
\hline No DM2 & $G(12 \%)$ & 100 & & & 100 & & & 100 & & & 1.00 & & & 1.00 & & \\
\hline $\begin{array}{l}\text { DM2: oral combination treatment } \\
\text { including metformin }\end{array}$ & $1(0.5 \%)$ & 0.38 & $0.05-273$ & 34 & 0.25 & $0.03-1.82$ & .17 & 0.23 & $0.03 \cdot 1.85$ & .17 & 0.23 & $0.03 \cdot 1.85$ & .17 & 0.23 & $0.03-1.96$ & .17 \\
\hline $\begin{array}{l}\text { DM2 oral combination treatment } \\
\text { excluding metformin }\end{array}$ & $2(83 \%)$ & 7.36 & $1.92-28.28$ & .004 & 4.10 & $1.06-15.92$ & .04 & 3.79 & $0.82 \cdot 17.56$ & .09 & 3.63 & $0.82-16.18$ & .09 & 3.66 & $0.82 \cdot 16.26$ & .09 \\
\hline No DME & $G(12 \%)$ & 100 & & & 100 & & & 100 & & & 1.00 & & & 1.00 & & \\
\hline $\begin{array}{l}\text { DM2: treatment with glucosidase } \\
\text { inhibitors, sulfonylureas } \\
\text { or meelitinides }\end{array}$ & $10(23 \%)$ & 1.88 & $0.97-3.63$ & .06 & 1.15 & $0.59-2.25$ & .8 & 1.27 & $0.56 \cdot 2.90$ & 56 & 1.32 & $0.57-3.04$ & .52 & 1.31 & $0.56 \cdot 3.04$ & 53 \\
\hline DM2: monother apy with metformin & $3(17 \%)$ & 1.34 & $0.42-4.25$ & 62 & 0.86 & $0.27 \cdot 2.80$ & 81 & 0.93 & $0.29 \cdot 2.99$ & .90 & 0.94 & $0.29 \cdot 3.06$ & 92 & 0.93 & $0.28-3.02$ & 90 \\
\hline DM2: any other medication & $14(48 \%)$ & 3.80 & $2.14-6.77$ & $<.001$ & 2.86 & $1.60-5.12$ & $=001$ & 3.26 & $1.51 \cdot 7.06$ & .003 & 3.34 & $1.52 \cdot 7.35$ & .003 & 3.31 & $1.50 \cdot 7.30$ & .003 \\
\hline
\end{tabular}

\section{Acknowledgment}

Diabetes Cardiovascular Risk and Evaluation: Targets and Essential Data for Commitment of Treatment (DETECT) is a cross-sectional and prospective, longitudinal, nationwide clinical epidemiological study. DETECT is supported by an unrestricted educational grant from Pfizer, Karlsruhe, Germany. Members of the DETECT Study Group are as follows: (principal investigator) Prof Dr H-U Wittchen; (staff members) Dipl.-Psych. L Pieper, Dipl.-Math. J Klotsche, Dr T Eichler, Dr H Glaesmer, E Katze. Steering Committee: Prof Dr H Lehnert (Lübeck), Prof Dr GK Stalla (München), Prof Dr AM Zeiher (Frankfurt); Advisory Board: Prof DrWMärz (Heidelberg/Graz), Prof Dr S Silber (München), Prof Dr U Koch (Hamburg), Priv.- Doz. Dr D Pittrow (München/Dresden), Prof Dr M Wehling (Mannheim), Dr D Leistner (Frankfurt), Priv.-Doz. Dr H J Schneider (München), Dr C Sievers (München).

DMB and SNK were supported by the Assistance to Firefighters grants program managed by the Federal Emergency Management Agency in the Department of Homeland Security EMW2006-FP-01493 and EMW-FP-00835.

DMB analyzed the data, wrote, and edited the manuscript; JK analyzed the data, revised/edited the manuscript; O-PH wrote the manuscript; CS contributed to the discussion; LP and H-UW collected the data, revised/edited the manuscript; GKS, RMS, and SNK contributed to the discussion; CSM designed the study, analyzed the data, and wrote the manuscript. 


\section{References}

[1] Coughlin SS, et al. Diabetes mellitus as a predictor of cancer mortality in a large cohort of US adults. Am J Epidemiol 2004;159:1160-7.

[2] Larsson SC, Mantzoros CS, Wolk A. Diabetes mellitus and risk of breast cancer: a meta-analysis. Int J Cancer 2007;121:856-62.

[3] Vigneri P, et al. Diabetes and cancer. Endocr Relat Cancer 2009;16:1103-23.

[4] Wild S, et al. Global prevalence of diabetes: estimates for the year 2000 and projections for 2030. Diabetes Care 2004;27:1047-53.

[5] Giovannucci E, Michaud D. The role of obesity and related metabolic disturbances in cancers of the colon, prostate, and pancreas. Gastroenterology 2007;132:2208-25.

[6] Bowker SL, et al. Increased cancer-related mortality for patients with type 2 diabetes who use sulfonylureas or insulin. Diabetes Care 2006;29:254-8.

[7] Currie CJ, Poole CD, Gale EA. The influence of glucose-lowering therapies on cancer risk in type 2 diabetes. Diabetologia 2009;52:1766-77.

[8] Monami M, et al. Treatment with insulin secretagogues and cancer-related mortality in type 2 diabetic patients a retrospective cohort study. Exp Clin Endocrinol Diabetes 2008;116:184-9.

[9] Yang YX, Hennessy S, Lewis JD. Insulin therapy and colorectal cancer risk among type 2 diabetes mellitus patients. Gastroenterology 2004;127:1044-50.

[10] Evans JM, et al. Metformin and reduced risk of cancer in diabetic patients. BMJ 2005;330:13045 .

[11] Landman GW, et al. Metformin associated with lower cancer mortality in type 2 diabetes:

ZODIAC-16. Diabetes Care 2010;33:322-6.

[12] Libby G, et al. New users of metformin are at low risk of incident cancer: a cohort study among people with type 2 diabetes. Diabetes Care 2009;32:1620-5.

[13] Monami M, et al. Sulphonylureas and cancer: a case-control study. Acta Diabetol 2009;46:27984.

[14] Gerstein HC. Does insulin therapy promote, reduce, or have a neutral effect on cancers? JAMA 2010;303:446-7.

[15] Schneider HJ, et al. Prevalence of low male testosterone levels in primary care in Germany: cross-sectional results from the DETECT study. Clin Endocrinol (Oxf) 2009;70:446-54.

[16] Sievers C, Schneider HJ, Stalla GK. Insulin-like growth factor-1 in plasma and brain: regulation in health and disease. Front Biosci 2008;13:85-99.

[17] Wittchen HU, et al. Cardiovascular risk factors in primary care: methods and baseline prevalence rates-the DETECT program. Curr Med Res Opin 2005;21:619-30.

[18] Nath N, et al. Metformin attenuated the autoimmune disease of the central nervous system in animal models of multiple sclerosis. J Immunol 2009;182:8005-14.

[19] Oba S, et al. Self-reported diabetes mellitus and risk of mortality from all causes, cardiovascular disease, and cancer in Takayama: a population-based prospective cohort study in Japan. J Epidemiol 2008;18:197-203.

[20] Ogunleye AA, et al. A cohort study of the risk of cancer associated with type 2 diabetes. $\mathrm{Br} \mathbf{J}$ Cancer 2009;101: 1199-201.

[21] Campbell RK. Type 2 diabetes: where we are today: an overview of disease burden, current treatments, and treatment strategies. J Am Pharm Assoc (2003) 2009;49(Suppl 1):S3-9. 